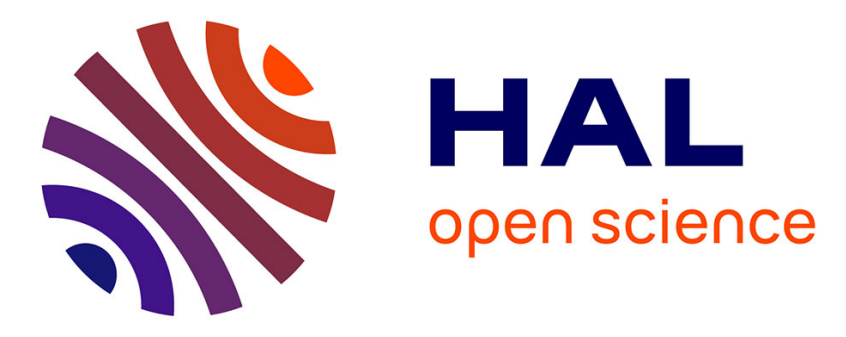

\title{
Precise position control of a travelling wave ultrasonic motor
}

Frédéric Giraud, Betty Lemaire-Semail, Julien Aragones, Jacques Robineau, Jean-Thierry Audren

\section{- To cite this version:}

Frédéric Giraud, Betty Lemaire-Semail, Julien Aragones, Jacques Robineau, Jean-Thierry Audren. Precise position control of a travelling wave ultrasonic motor. IEEE Transactions on Industry Applications, 2005, 6 (3), pp.1548 - 1554. 10.1109/TIA.2007.900463 . hal-01110737

\section{HAL Id: hal-01110737 \\ https://hal.science/hal-01110737}

Submitted on 28 Jan 2015

HAL is a multi-disciplinary open access archive for the deposit and dissemination of scientific research documents, whether they are published or not. The documents may come from teaching and research institutions in France or abroad, or from public or private research centers.
L'archive ouverte pluridisciplinaire HAL, est destinée au dépôt et à la diffusion de documents scientifiques de niveau recherche, publiés ou non, émanant des établissements d'enseignement et de recherche français ou étrangers, des laboratoires publics ou privés. 


\title{
Precise Position Control of a Travelling Wave Ultrasonic Motor
}

\author{
Frédéric Giraud, Betty Lemaire-Semail \\ Laboratory of electrotechnics and power electronics of Lille \\ Avenue Paul Langevin \\ 59655 Villeneuve d'Ascq Cedex France \\ Email: first name.name@polytech-Lille.fr \\ Julien Aragones, Jacques Robineau Jean-Thierry Audren \\ SAGEM défense sécurité \\ Le Ponant de Paris, 27 rue Leblanc \\ 75512 Paris Cedex 15, France \\ Email: first name.name@sagem.com
}

\begin{abstract}
Precise position control of a Travelling Wave UItrasonic Motor is achieved, avoiding the traditional drawbacks attributable to non-linear torque generation: overshoot or slow response time. For that purpose, a behavior model control is proposed and presented. With this control law, a quick and precise response is obtained. In this article, we present a position control scheme of an inertial load. The guideline used for this control was a rotation of $90^{\circ}$ in a response time of about $200 \mathrm{~ms}$ with a position error of $0.6 \mathrm{mrad}$, targeting a typical application for avionics. In the paper, a shinsei USR30 is used, but the method can be applied to other Ultrasonic Motors.
\end{abstract}

\section{INTRODUCTION}

Travelling Wave Ultrasonic Motors (TWUM) exploit a piezoelectrically generated flexural wave which propagates at the surface of a stator. This wave is able to propel by contact a rotor strongly pressed on it. The friction that the contact mechanism produces is at the origin of numerous advantages, among which we can find: holding torque without supply, a high torque to mass ratio and high torque - low speed characteristics. Thus, while a speed reducer is often needed with an electromagnetic motor, it becomes unnecessary in an application using TWUM, leading to lightweight and compact applications. These features increase significantly the interest of avionics in these motors; they can be used for example for finely positioning optical lenses in embedded optronic devices.

Unfortunately, the torque generated by a TWUM is non linear: it depends on the rotational speed, and a large static friction torque appears at low speed; in that context, position controls are not straightforward and often fail in applications where precise position and robustness are both required. Simple position correctors are not sufficiently robust compared to external load torque or parameters variations, since they are better suited to roughly linear process.

On the one hand, it has been shown, for example in [1], that to obtain torque at low rotational speed, and thus attain good position error, it is useful to change the temporal phase shift between the two supply voltages. On the other hand, some authors experimented with many techniques to achieve robustness in position controls, for example adaptive controls [2], fuzzy-logic [3] and neural networks [4][5] are used to make up for lack of knowledge about the motor and its load. Robustness and precision are thus obtained, but at the expense of tuning complexity, while transient performances overshoot and response time - are not compared.

In the present paper we propose a position control of an inertial load actuated by a TWUM which requires robustness, precision and short response time. It is based on a coarse but causal modelling of the motor which is presented in section II. The controller presented doesn't belong to adaptive controllers family, but the non-linearities and the parameters changes are compensated thanks to a behavioral model control which will be described in section III. At last, the actuator's behavior will be checked by experimental results.

\section{Modelling OF THE TORQUE GENERATION}

\section{A. Modelling overview.}

Each sinusoidal voltage, named $v_{\alpha}$ and $v_{\beta}$, supplying the motor creates a stationary flexural waves, $w_{\alpha}$ and $w_{\beta}$, which bends the stator. Superimposing both standing waves creates an elliptical motion of the stator's particles. This motion creates frictional forces which are at the origin of the torque. A detailed description of the principles of the propagation of the wave can be found in [6]. As for [7], we developed an analytical modelling of the stator's vibration from which a causal modelling is derived [8]. However, in this article, we focus our attention on torque generation. This is why it is supposed that control of the two stationary waves is obtained by an external loop. Considering that no cross couplings between the two phases exists, the following equations will be admitted:

$$
\begin{array}{cc}
w_{\alpha}(t)=W \sin (2 \pi f t) & w_{\beta}(t)=W \sin (2 \pi f t-\varphi) \\
v_{\alpha}(t)=V \sin (2 \pi f t+\Psi) & v_{\beta}(t)=V \sin (2 \pi f t+\Psi-\varphi)
\end{array}
$$

with $W$ the stator's deformation amplitude, $V$ the supply voltage amplitude and $f$ the voltage's frequency. 


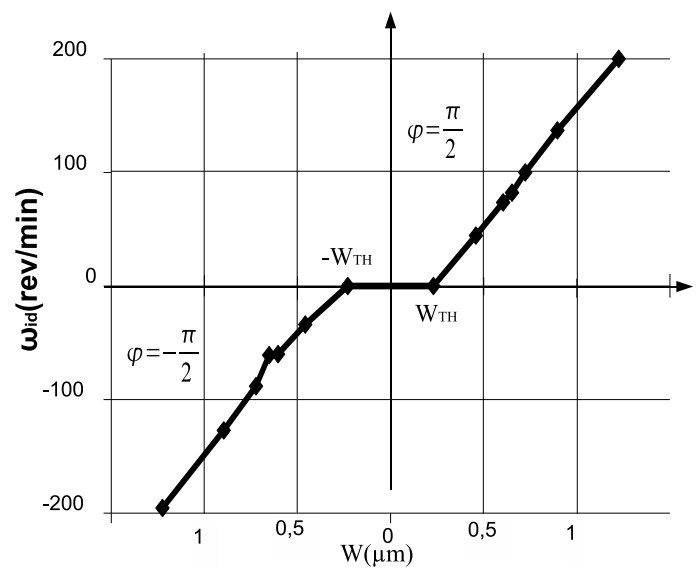

(a) $\omega_{i d}$ as a function of $W$.

Fig. 1. Identification of $\omega_{i d}$

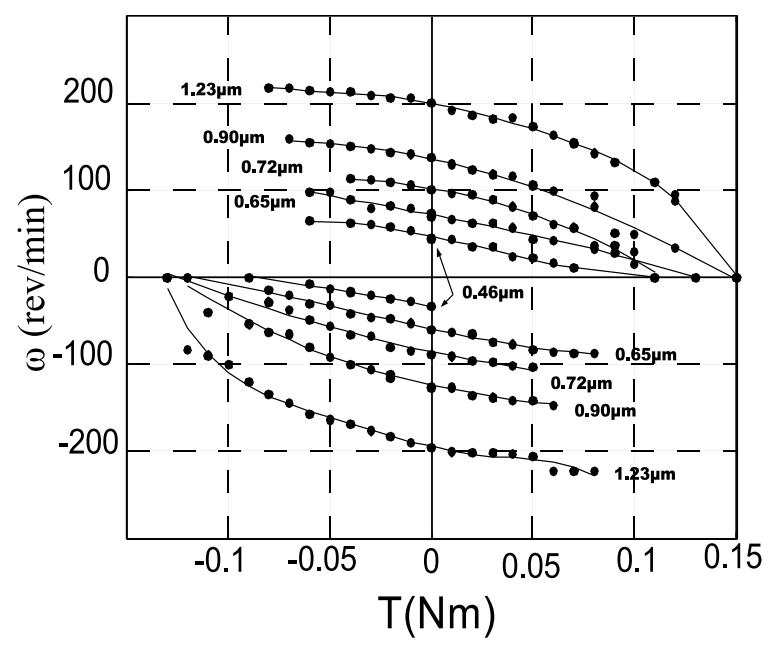

(a) Torque-speed characteristics at $W$ constant. $\varphi= \pm \frac{\pi}{2}$

Fig. 2. Characteristics of the loaded motor.

In normal operating mode, $\varphi$ is set to $\frac{\pi}{2}$ for a positive rotational speed, and to $-\frac{\pi}{2}$ for a negative one. But in order to improve performances at low rotational speed, variations of $\varphi$ in the range of $\left[-\frac{\pi}{2} ; \frac{\pi}{2}\right]$ will be applied.

To describe the torque generation process, we previously introduced the ideal rotational speed $\omega_{i d}$ [8][9]; $\omega_{i d}$ is assumed to be the rotational speed of the rotor under ideal contact position: no slippage between stator and rotor and a punctual contact. A kinematic study of the stator [9] helps to express the value of $\omega_{i d}$ which is given by:

$$
\omega_{i d}=(2 \pi f) k \frac{h}{b^{2}} W \sin (\varphi)
$$

with the following constant parameters

- $k$ : wavenumber of the stator

- $b$ : radius of the stator,

- $h$ : thickness of the stator.

It should be noted here that the stator is a mechanical resonator, and the vibration amplitude is named $W$. So, the voltages of frequency $f$ are tuned in close vicinity of the

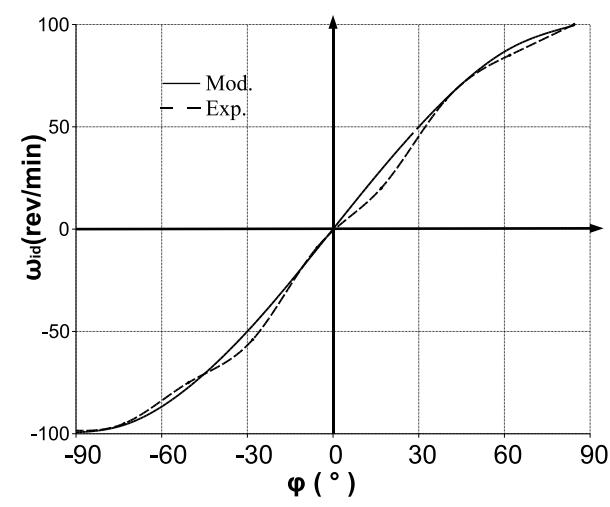

(b) $\omega_{i d}$ as a function of $\varphi$; experimental and modeling $(W=0,65 \mu m)$

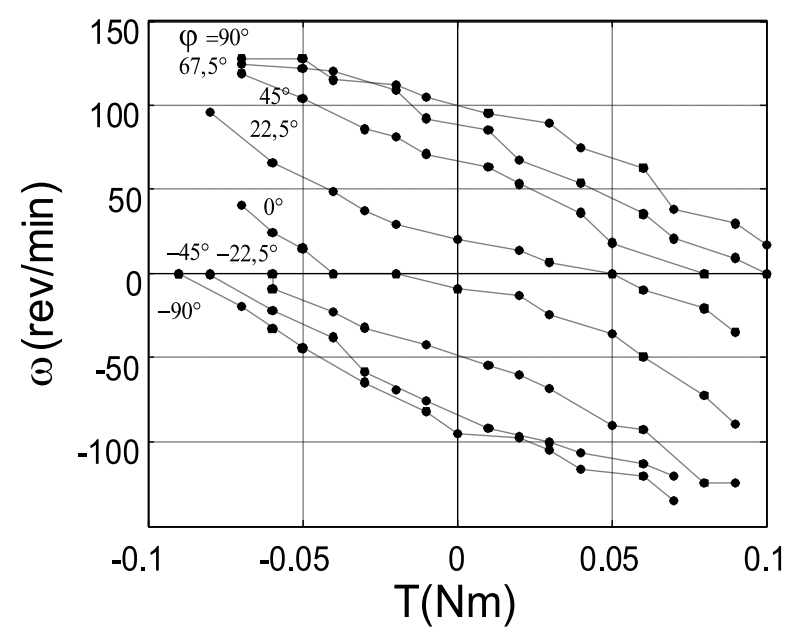

(b) Torque-speed characteristics for several values of $\varphi$; W= $0,65 \mu \mathrm{m}$.

eigenfrequency: in equation $3, f$ can be considered constant. Modification of $\omega_{i d}$ is achieved by tuning $f$, but for the sole purpose of tuning $W$ thanks to the resonant process.

However, due to the stator/rotor contact mechanism, the actual speed of the rotor $\omega$ is different from $\omega_{i d}$. First, because at low wave amplitude, stick-slip effect causes tribological uncertainties which stop the motor. This is illustrated in figure 1(a) on the measured curve of the no load speed of the motor as a function of $W$ where a dead zone around $W=0$ appears. One way to reduce this dead-zone effect is to change the temporal phase shift of the supply voltages. For a constant wave amplitude $W$ above a threshold - named $W_{T H}-$, and a varying $\varphi, \omega_{i d}$ decreases, and the dead-zone disappears, as depicted figure 1(b), on which we recognize the sinusoidal shape of equation 3. Second, because the motor decelerates when it is loaded by an external load torque $T_{r}$. On the figure 2, we have drawn the torque-speed characteristics of the motor for a constant $\omega_{i d}$ (either by keeping $\varphi$ constant or $W$ constant). 
So, these experimental runs highlight many nonlinearities in the torque generation. Modelling exists for describing the stator/rotor contact mechanism; for example, by using Coulomb's friction law [10] which can be extended to take into account many nonlinear mechanisms, such as the tangential deformation of the contact layer [11]. However, this modelling is suited to simulation or prototyping of the motors, and becomes very complex when we attempt to build a control scheme from it. This is why we aim to define a simpler modelling.

\section{B. Simplified Modelling}

The proposed simplified modelling is obtained by making a linear approximation of the torque-speed characteristics. The torque $T$ produced by the motor can be thus written as

$$
R_{1} \longrightarrow T=f_{0}\left(\omega_{i d}-\omega\right)
$$

$f_{0}$ can be identified by measuring the average slope of the curves of the figures 2, while $W_{T H}$ is a threshold measured for $\varphi= \pm \frac{\pi}{2}$. The dead-zone effect can then be modelled by revising the equation 3 :

$$
\begin{aligned}
& R_{2} \longrightarrow \omega_{i d} \text { with } \\
& \omega_{i d}=(2 \pi f) k \frac{h}{b^{2}}\left(W-W_{T H}\right) \sin (\varphi) \text { if } \quad W>W_{T H} \\
& \omega_{i d}=0 \quad \text { if } 0<W<W_{T H}
\end{aligned}
$$

Finally, the dynamic of the rotor in the tangential direction can be given by the equation 7 :

$$
J \frac{d \omega}{d t}=T-T_{r}
$$

This set of equations, giving a simplified description of the torque generation, can be represented using the Causal Ordering Graph (COG - [12]). This graphical description tool of physical systems first defines two kinds of model for elementary objects: a causal processor is associated with an energy storage object and is represented by an oriented arrow symbol. Symbols with a bidirectional arrow are associated with dissipative objects as well as instantaneous relations. To match the requirement of causality in the representation, equation 7 must be revised to:

$$
R_{3} \longrightarrow \omega=\frac{1}{J} \int\left(T-T_{r}\right) d t
$$

The COG of the TWUM is then represented in figure 3 . In this modelling, the relations which are not linear are highlighted by a double circle. The parameters, whose values are given table I, are identified as follow:

- $f_{0}$ is directly given by the average slope of figure 2,

- $k \frac{h}{b^{2}}$ is given by the slope of figure 1(a) (whose actual slope is in fact $(2 \pi f) k \frac{h}{b^{2}}$ according to 3$)$

- $W_{T H}$ is given by the dead-zone of figure 1(a)

The response of this modelling is compared to experimental measurements (figure 4) for a step of $W$ from $0,77 \mu \mathrm{m}$ to $0,94 \mu \mathrm{m}$. Both responses are consistent, checking the validity of the modelling, where $f_{0}$ is almost constant at the most.

This modelling is the basis of the position controller; the next section describes the calculation of the regulator's parameters.

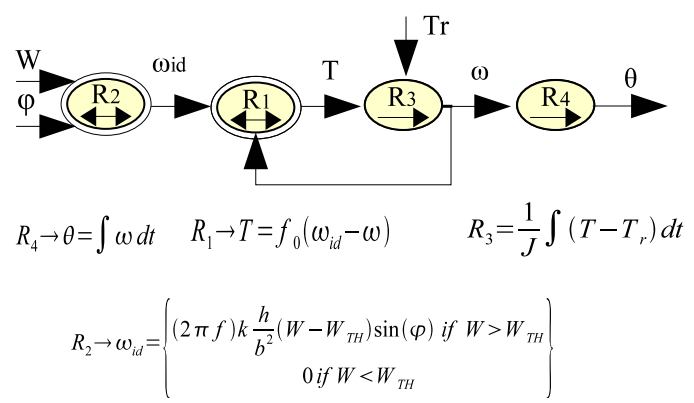

Fig. 3. COG of the TWUM

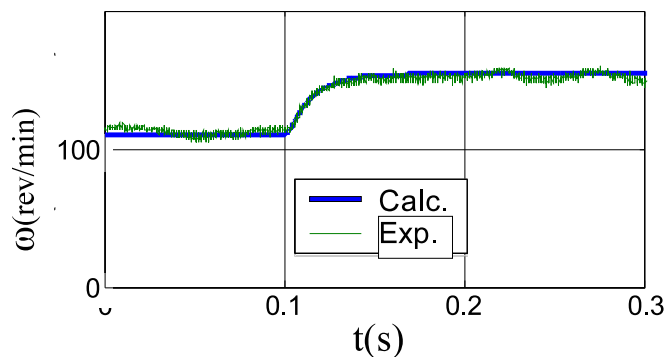

Fig. 4. Transitory step response of the speed of the motor. Comparison with the measurement.

TABLE I

PARAMETERS IDENTIFICATION FOR USR30 AND ITS LOAD

\begin{tabular}{|c|c|c|c|}
\hline$f_{0}$ & $J$ & $k \frac{h}{b^{2}}$ & $W_{T H}$ \\
\hline $0.0224 N . m . s$ & $10^{-4} \mathrm{~kg} . \mathrm{m}^{2}$ & $70 \mathrm{~m}^{-} 1$ & $0,28 \mu m$ \\
\hline
\end{tabular}

\section{ROBUST AND PRECISE POSITION CONTROL}

\section{A. Introduction}

When the modelling is represented by a COG, the control laws can be deduced by inversion of the graph [12]. Since we have separated causal and instantaneous relations in the modelling, we operate differently for each case (figure 5). For instance, an instantaneous relation can be directly inverted :

$$
\text { if } \quad R \rightarrow y=R(u) \quad \text { then } \quad R_{c} \rightarrow u_{R E G}=C\left(y_{R E F}\right)
$$

and $y=y_{R E F}$ if $C=R^{-1}$.

A causal relation can't be directly inverted. So, a control loop is achieved, which then requires a feedback:

$$
\text { if } \quad R \rightarrow y=R(u) \quad \text { then } \quad R_{c} \rightarrow u_{R E G}=C\left(y_{R E F}-y\right)
$$

and $y=y_{R E F}$ if $C \rightarrow \infty$.

Thus, it is now possible to deduce the position control law by inverting the COG of figure 3 .

Among the possible strategies, the one depicted on figure 6 is a position control with a speed control in serial. The output of the speed controller $\left(R_{c 3}\right)$ is a reference for the torque; however, on TWUM, the torque cannot be directly controlled by an electrical variable - a current or a voltage as in the case of electromagnetic motors. Thus, $R_{1}$ has to be 


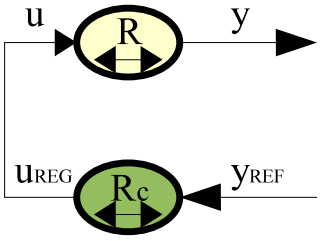

(a) Instantaneous relation

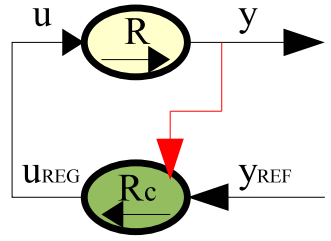

(b) Causal relation
Fig. 5. Inversion of elementary processors [12].

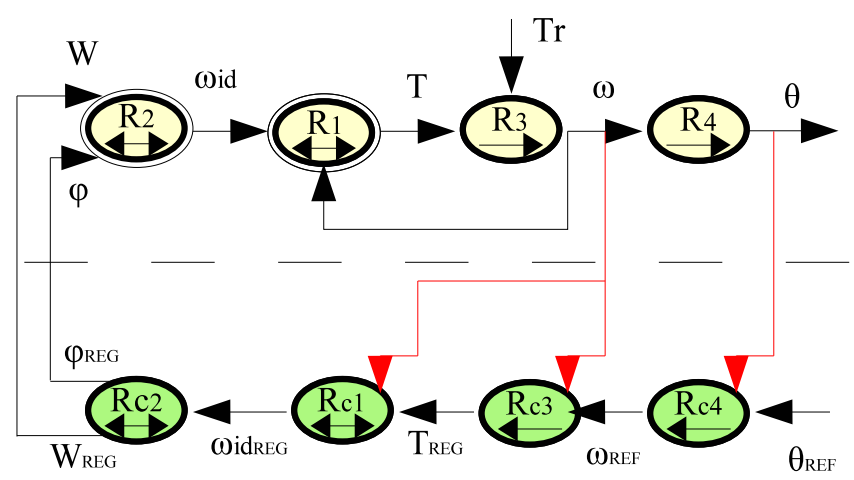

Fig. 6. COG of a position control scheme.

inverted, and this is the function of $R_{c 1}$. Since $f_{0}$ varies with the operating point, $R_{1}$ and $R_{2}$ are strongly non-linear; their inversion, based on a linear expression, leads to slow dynamic responses and static error. This is why, in [13] a neural network is used to inverse the contact model and compensate the nonlinear torque generation. Good results are thus obtained at the expense of control complexity. The control presented in the next section uses linear controller only. But the overall scheme helps to compensate the parameters variations.

\section{B. Behavior model control}

Behavior Model Control (BMC) has been successfully applied to electromagnetic motors control to solve the unknown parameters variations or to remove the effect of nonlinearity [14]. This is why we experimented with this control scheme in our application.

The basic principle of BMC relies on a linear modelling of the process with constant parameters (the behavior model) . Together with the reference value, modelling output is used online to compute the error. This error is minimized by using a main controller $R M$. If the actual process is equal to its modelling, outputs of $R M$ should be sufficient for controlling it with respect to the reference. But because discrepancy between the actual process and the simplified modelling exists, there may be some difference between their outputs.So, behavior controller, $R B$ is used to remove the difference between the actual process and its modelling. Controllers output are both applied to the tuning input of the process. To sum up, the behavior controller has to enforce the actual process to follow the simplified modelling behavior. As for the main controller, it is able to impose the closed-loop dynamic. The actual outputs of the motor behave like if linear at the condition that the behavior controller is faster than the main one [15].

Figure 7 depicts the overall scheme of the $B M C$ designed for a state space control. For a better comprehension, in this modelling the input of the Behavior Model is $\omega_{i d M}$, the inversion of $R_{2}$ is achieved for the actual motor and will be detailed in section III-B.3. We are now detailing the calculation of the controller $R_{M}$ and $R_{B}$.

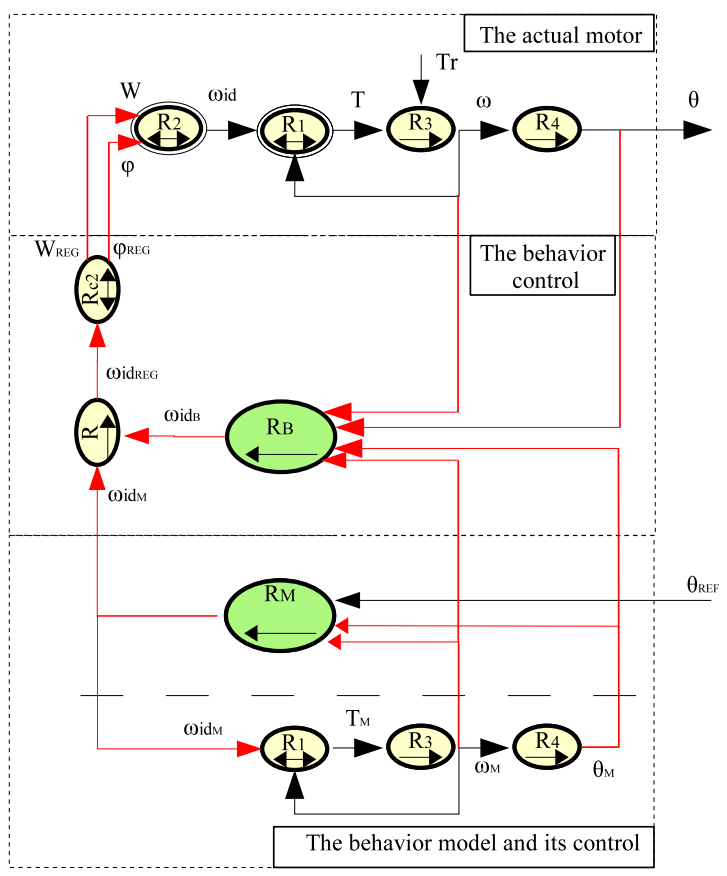

Fig. 7. COG of a the Behavior Model Control.

1) Calculation of the Main Controller: The corrector is based on a linearized modelling of the TWUM established in section II. For that purpose, the non linearities are removed and a state space modelling is used yielding:

$$
\dot{X}_{M}=A_{M} X_{M}+B_{M} \omega_{i d M}
$$

with the state vector defined as

$$
\begin{aligned}
X_{M} & =\left(\begin{array}{c}
\theta_{M} \\
\omega_{M}
\end{array}\right) \\
A_{M} & =\left(\begin{array}{cc}
0 & 1 \\
0 & -\frac{f_{0}}{J}
\end{array}\right) \\
B_{M} & =\left(\begin{array}{c}
0 \\
\frac{f_{0}}{J}
\end{array}\right)
\end{aligned}
$$

The control of the TWUM is deduced from a state space control:

$$
\begin{aligned}
R_{M} \rightarrow \omega_{i d M} & =K\left(X_{M r e f}-X_{M}\right) \\
& =\left(K_{1} ; K_{2}\right)\left(X_{M r e f}-X_{M}\right)
\end{aligned}
$$

with

$$
X_{\text {ref }}=\left(\begin{array}{c}
\theta_{r e f} \\
0
\end{array}\right)
$$


The characteristic polynomial $P_{M}(s)$ for this closed-loop system is the determinant of $s I-\left(A_{M}-B_{M} K\right)$. This yields

$$
P_{M}(s)=1+2 \frac{\xi}{\omega_{0}} s+\frac{s^{2}}{\omega_{0}}
$$

with

$$
\omega_{0}^{2}=\frac{f_{0}}{J} K_{1} \quad \xi=\frac{1}{2 \omega_{0}}\left(1+K_{2}\right) \frac{f_{0}}{J}
$$

The parameters $K_{1}$ and $K_{2}$ are then calculated so as to match the requirements of the guidelines, i.e. $\xi=1$ and $\omega_{0}=38 \mathrm{rad} / \mathrm{sec}$, which corresponds to a step response time of $200 \mathrm{~ms}$ with no overshoot. The values of $K_{1}$ and $K_{2}$ are given in table II.

TABLE II

VALUES OF THE CORRECTOR

\begin{tabular}{|c|c|}
\hline$K_{1}$ & $K_{2}$ \\
\hline $7,1 s^{-1}$ & $-0,71$ \\
\hline
\end{tabular}

2) calculation of the behavior corrector: The method described in the previous section is applied to the calculation of the behavior corrector; however, because no static error between the outputs of the simulated and actual motor is allowed, the state vector is upgraded to include the integrative value of $\theta$ :

$$
\dot{X}_{B}=A_{B} X_{M}+B_{B} \omega_{i d B}
$$

with the state vector defined as

$$
\begin{aligned}
X_{B} & =\left(\begin{array}{c}
\int \theta \\
\theta \\
\omega
\end{array}\right) \\
A_{B} & =\left(\begin{array}{ccc}
0 & 1 & 0 \\
0 & 0 & 1 \\
0 & 0 & -\frac{f_{0}}{J}
\end{array}\right) \\
B_{B} & =\left(\begin{array}{c}
0 \\
0 \\
\frac{f_{0}}{J}
\end{array}\right)
\end{aligned}
$$

Once again, the control of the simulated TWUM is deduced from a state space control:

$$
\begin{aligned}
R \rightarrow \omega_{i d B} & =G\left(X_{\text {Bref }}-X_{B}\right) \\
& =\left(G_{1} ; G_{2} ; G_{3}\right)\left(X_{\text {Bref }}-X_{B}\right)
\end{aligned}
$$

with

$$
X_{\text {Bref }}=\left(\begin{array}{c}
\int \theta_{M} \\
\theta_{M} \\
\omega_{M}
\end{array}\right)
$$

And the characteristic polynomial $P_{B}(s)$ for this closedloop system is also the determinant of $s I-\left(A_{B}-B_{B} G\right)$ :

$$
P_{B}(s)=G_{1} \frac{f_{0}}{J}+G_{2} \frac{f_{0}}{J} s+\frac{f_{0}}{J}\left(1+G_{3}\right) s^{2}+s^{3}
$$

Since $P_{B}$ is a third order type polynomial, we can chose the location of the roots in order to fulfill the requirements of the guideline. This can be achieved using Naslin's empirical procedure [16]. Given a polynomial with real positive coefficients:

$$
P(s)=a_{0}+a_{1} s+a_{2} s^{2}+\ldots+a_{n-1} s^{n-1}+a_{n} s^{n} \quad a_{i}>0
$$

we introduce the following characteristic pulsatances:

$$
\beta_{0}=\frac{a_{0}}{a_{1}}, \quad \beta_{1}=\frac{a_{1}}{a_{2}}, \quad \ldots, \quad \beta_{n-1}=\frac{a_{n-1}}{a_{n-2}}
$$

and the ratios:

$$
\alpha_{1}=\frac{a_{1}^{2}}{a_{0}} a_{2}, \quad \alpha_{2}=\frac{a_{2}^{2}}{a_{1}} a_{3} \quad \ldots \quad \alpha_{n-1}=\frac{a_{n-1}^{2}}{a_{n-2}} a_{n}
$$

It can be shown that if those ratios have the same value, named $\alpha$ the principal characteristic ratio, and are bigger than 2 , the transient response is equivalent to a second order response with a "good" damping and the rising time of the step response is given by:

$$
t_{D} \approx \frac{2,2}{\beta_{0}}
$$

In this article, good results have been obtained for $t_{D}=$ $60 \mathrm{~ms}$ and $\alpha=2.8 \mathrm{~ms}$. So, considering equations 25,27 and 28 , leads to the expressions and the values of $G_{1}, G_{2}$ et $G_{3}$ summarized at table III:

TABLE III

EXPRESSION AND CALCULATED VALUE OF THE BEHAVIOR CORRECTOR

\begin{tabular}{|c|c|c|}
\hline$G_{1}$ & $G_{2}$ & $G_{3}$ \\
\hline $98,6.10^{3} s^{-2}$ & $1,5.10^{3} s^{-1}$ & 3,58 \\
\hline
\end{tabular}

We have designed the controllers for the behavior model control $R_{M}$ and $R_{B}$. They are calculated for a specific value of $\mathrm{J}$. This suits well for our application where the load is supposed to be a pure and constant inertial load. But the controller still remains stable with good performances in the case of extra load torque and small variations $(100 \%)$ of the parameter J [17]. If larger variations are experienced, we should estimate on line its value and adapt the controllers parameters; or design a non linear adaptive controller, such as [18].

Now we still have to inverse relation $R_{2}$ to obtain $R_{c 2}$ (see figure 7). This is dealt with in the next section.

3) phase difference control: For the very low values of $\omega_{i d}$, it is known that $W$ should not be decreased below a threshold $\left(W_{T H}\right.$, figure 1(a)). Because in this condition the rotor sticks on the stator, we would rather keep $W$ constant and adjust $\varphi$ so as to attain the right value for $\omega_{i d}$. We then define $W_{M i n}$, the lowest value for $W$, with $W_{M i n}>W_{T H}$ and we have chosen the following strategy for $R_{c 2}$ :

$$
R_{c 2} \rightarrow \quad(W, \varphi)=f\left(\omega_{i d R E G}\right)
$$

with

$$
W=\sup \left(W_{M i n}, \frac{1}{k \frac{h}{b^{2}}(2 \pi f)}\left|\omega_{i d R E G}\right|+W_{T H}\right)
$$

and 


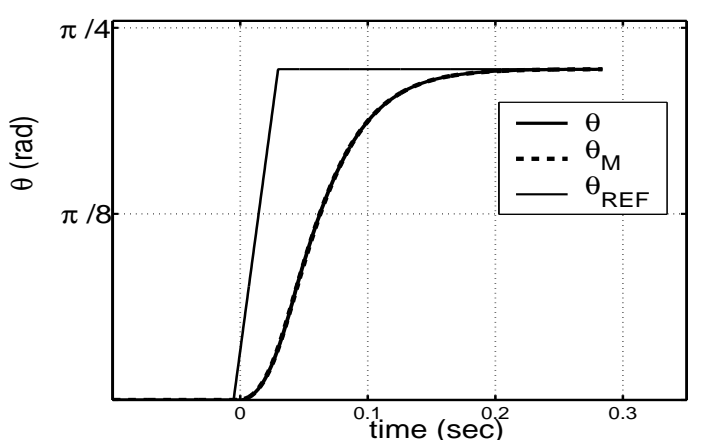

(a) Evolution of $\theta_{R E F}, \theta_{M}$ and $\theta$

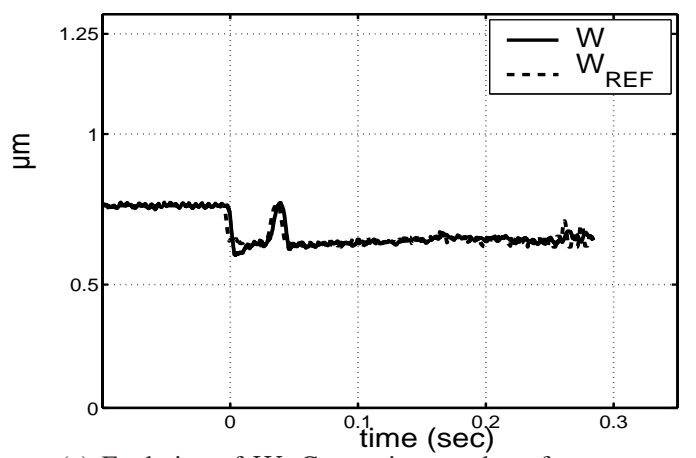

(c) Evolution of $W$. Comparison to the reference

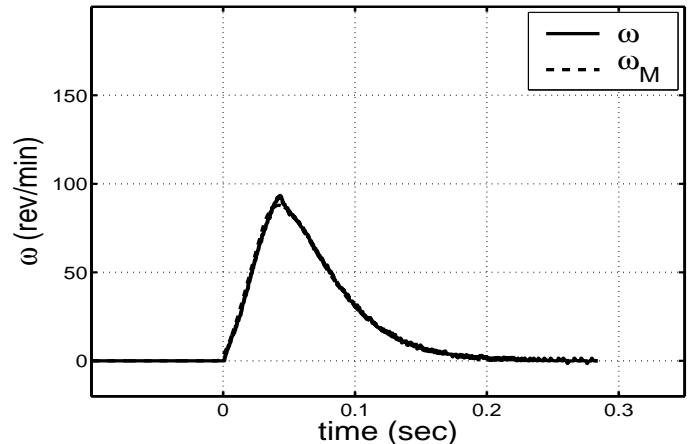

(b) Evolution of $\omega_{M}$ and $\omega$

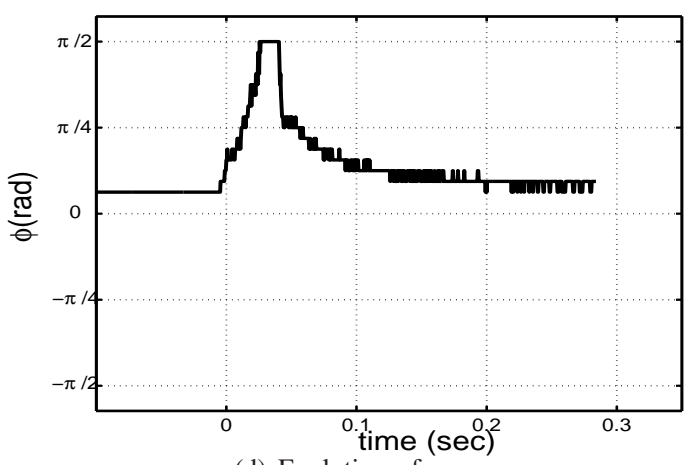

(d) Evolution of $\varphi$

Fig. 8. Small step response of the motor - first run.

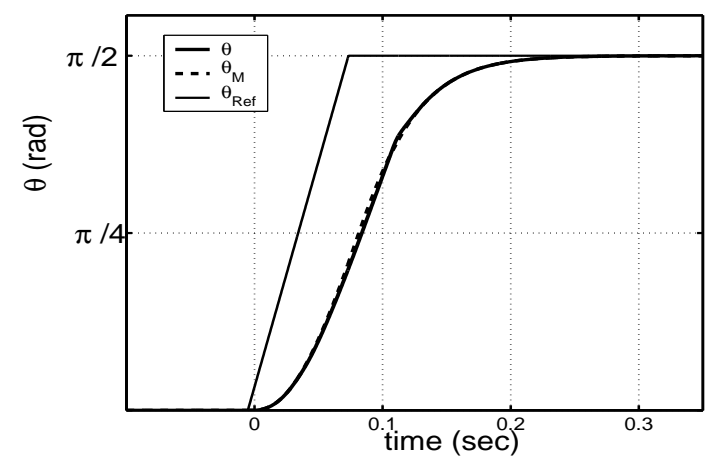

(a) Evolution of $\theta_{R E F}, \theta_{M}$ and $\theta$

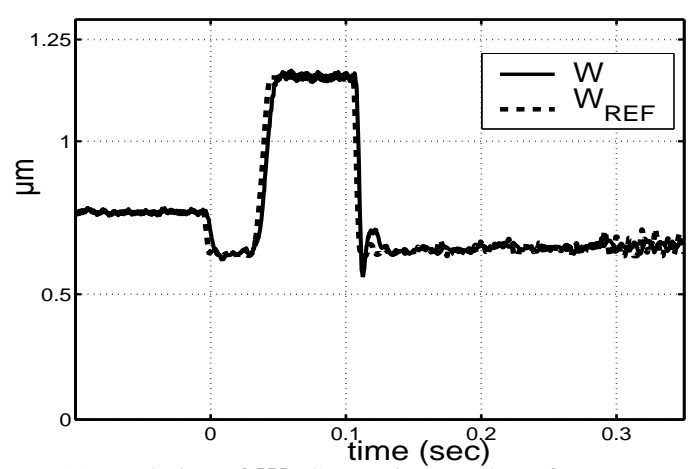

(c) Evolution of $W$. Comparison to the reference

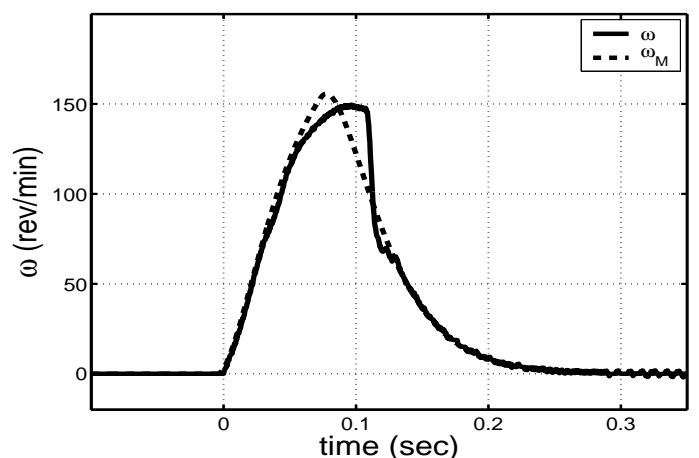

(b) Evolution of $\omega_{M}$ and $\omega$

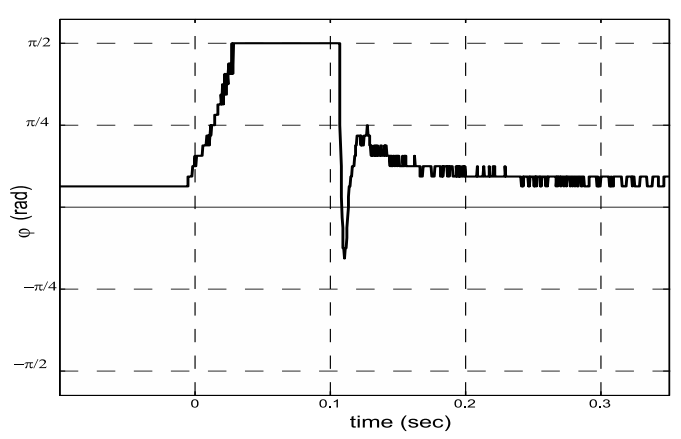

(d) Evolution of $\varphi$

Fig. 9. Big step response of the motor - second run. 
$\varphi=\left\{\begin{array}{ccc}\frac{\omega_{i d}}{\left|\omega_{i d}\right|} \cdot \frac{\pi}{2} \quad \text { if } & \left|\omega_{i d R E G}\right|>(2 \pi f) k \frac{h}{b^{2}}\left(W_{M i n}-W_{T H}\right) \\ & \operatorname{else} \\ & \arcsin \left(\frac{\omega_{i d R E G}}{(2 \pi f) k \frac{h}{b^{2}}\left(W_{M i n}-W_{T H}\right)}\right)\end{array}\right.$

This strategy is summarized by figure 10 .
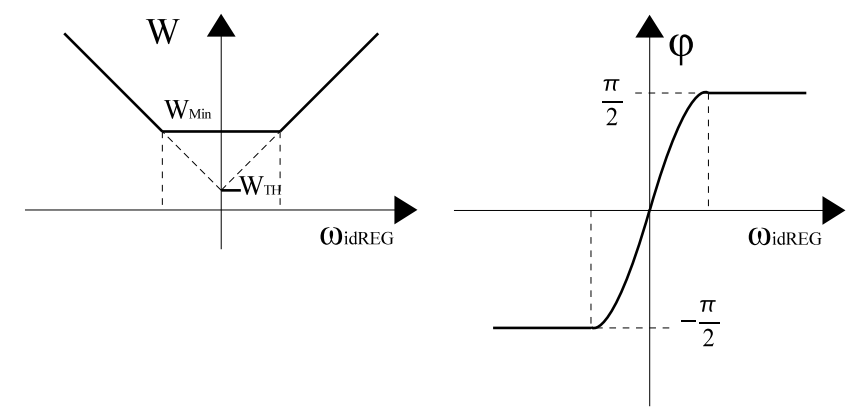

(a) $W$ as a function of $\omega_{i d}$ (b) $\varphi$ as a function of $\omega_{i d}$

Fig. 10. Computation of $W$ and $\varphi$. Inversion of $R_{2}$

Finally, the reference value of $W$ has been saturated to avoid stator damage.

\section{EXPERIMENTAL RUNS}

\section{A. Experimental setup}

Experimental runs have been carried out to verify the performances of this control. The test bench is made using a shinsei USR30[19] and the supply voltages are produced by a linear power amplifier. The photograph of figure 11 shows the motor and its inertial load, attached to an optical encoder. This mechanical load provides the same behavior on the motor's shaft as the real optronic system the control is designed for. One will notice the size of the motor, which is small compared to the load (the motor inertia can in fact be neglected).

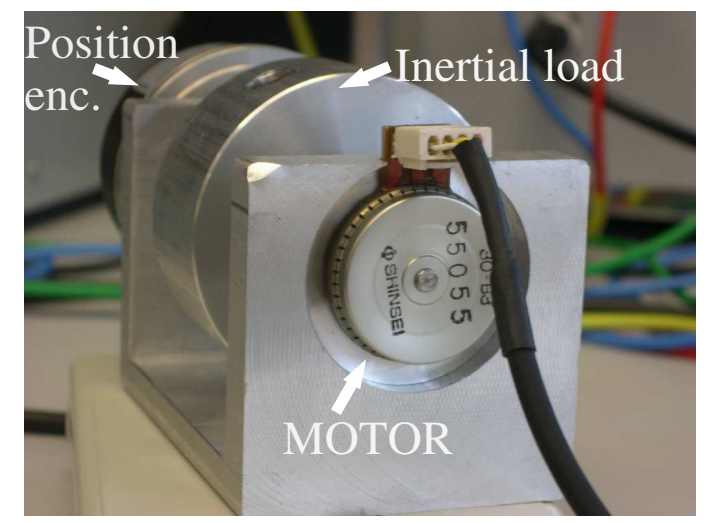

Fig. 11. Experimental setup with the shinsei $\phi 30 \mathrm{~mm}$ motor.

In the next section, the experimental trials are presented.

\section{B. experimental results}

For the first trial, the reference for $\theta_{R E F}$ is small. The evolutions of $\theta, \theta_{M}$ and $\theta_{R E F}$ are depicted on figure 8(a)

On this figure, $\theta_{M}$ respects the guidelines, because the response time is less than $200 \mathrm{~ms}$ and there is no overshoot. On the same figure the actual output of the motor is depicted; as one can see, $\theta$ follows $\theta_{M}$ and thus also respects the guideline. According to figure $8(\mathrm{~b})$, the actual revolving speed and the model's revolving speed are similar, excepting at the starting of the motor: this is due to the time response that exists between the stator's deformation amplitude $W$ and the actual deformation amplitude measured on the motor. This point is detailed on figure 8(c) where both measurement and reference of $W$ are depicted. On figure 8(d), the evolution of $\varphi$ is depicted. At $t=0, \varphi=\frac{\pi}{2}$ in order to have the most important torque. Then, as $\omega_{M}$ decreases, $\varphi$ also decreases according to figure 1(b). This strategy has been chosen to avoid small wave amplitude $W$, and thus avoid the dead-zone of figure 1(a). A fine position control is achieved since no stick-slip appears between stator and rotor. For steady state, $\varphi$ is set to a constant value (near 0 ) to compensate residual static friction on the shaft. Moreover, $\varphi$ increases gradually because the electronic device controlling $\varphi$ doesn't let continuous variation.

For the second trial, larger step responses are experimented with. Now, a bigger error is observed between $\theta$ and $\theta_{M}$ (figure 9(a). This is due to the saturation of $W$ which has been set in $R_{c 2}$. So, the speed of the motor is limited and can't be equal to the speed required to follow the behavior of model 9(b). But it is interesting to note that the motor catches up the trajectory of the model as soon as possible, avoiding any overshoot.

\section{Checking Robustness By SIMUlation}

During operation of the device, an external torque can be applied on the load; a position error can then appear if the control is not sufficiently robust. With a BMC, the robustness against perturbations is obtained by the behavior controller $R_{B}$, which is supposed to be faster than the main controller. This is why, rejection of perturbation is "good" with such a control scheme. This is confirmed by the simulations results

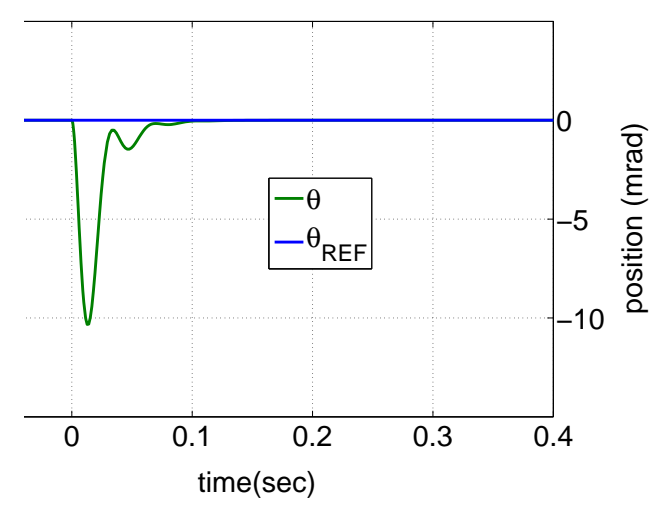

Fig. 12. Position error for a step torque variation. Simulation result; at $\mathrm{t}=0$, $T_{r}=0.05 \mathrm{Nm}$.

of the figure 12 which shows the position error to a step variation of the external torque of $0.05 \mathrm{Nm}$. The maximum error observed is $10 \mathrm{mrad}$, which is acceptable, compared to 
the resolution $-0.6 \mathrm{mrad}-$ of the guidelines. These results agree with the experiment, as detailed in [17].

This approach may also be applied for other typical load conditions. In particular, for large disturbance torque, or coulomb friction torque. Moreover, as far as a linear process modelling can be developed, the proposed BMC method can be used for other type of actuators. In the case of ultrasonic motors - which are typically non-linear - the main issue is then to deduce a modelling sufficiently simplified to come to a straightforward main controller, but also accurate enough to make the work of the behavior controller easier[8][20].

\section{CONCLUSION}

The aim of this paper was to achieve a precise position control of a TWUM for typical avionic applications in the field of optical lense positioning. Although the dynamic and mechanical properties of the actuator are interesting, its control is not straightforward, which accounts for the many non linearities of the contact phenomena at the stator/rotor interface.

To achieve a precise control, we propose both a modelling approach well adapted to control issue, and a behavior model control to cope with the modelling uncertainties. For that purpose, an experimental identification of the TWUM's mechanical characteristics has been achieved, allowing the building of a simplified modelling. The causal structure of position control was then built and the regulator's parameters determination was explained. After implementation, the control law was checked experimentally and showed dynamic responses which respect the guidelines, as well as good robustness behavior.

\section{REFERENCES}

[1] J. Maas, P. Ide, H. Grostollen, "Characteristics of inverter-fed ultrasonic motors," PESC'97 St Louis(USA), vol. 1, pp. 740-746, 1997.

[2] T.Senjyu, I. Miyazato, and K. Uezato, "Quick and precise positilon control of ultrasonic motors taking account of frictional force control," Thirtieth IAS Annual Meeting, IAS '95, vol. 1, pp. 85-89, Oct. 1995.

[3] F.-J. Lin, R.-J. Wai, C.-C Lee, "Fuzzy neural network position controller for ultrasonic motor drive using push-pull dc-dc converter," IEE Proc.Control Theory Appl.,, vol. 146, no. 1, pp. 99-107, Jan. 1999.

[4] T.Senjyu, I. Miyazato, and K. Uezato, "Position control of ultrasonic motors using neural network," Proceedings of the IEEE International Symposium on Industrial Electronics, 1996. ISIE '96., vol. 1, pp. 368373, June 1996.

[5] K. Tanaka, M. Oka, A. Uchibori, Y. Iwata, H. Morioka, "Precise position control of an ultrasonic motor using the pid controller combined with nn," Electrical Engineering in Japan, vol. 146, no. 3, pp. 46-54, 2004.

[6] Toshiiku Sashida, Takashi Kenjo, An introduction to Ultrasonic Motors. Clarendon Press, 1993.

[7] W. Hagood IV, A.J. McFarland, "Modeling of a piezoelectric rotary ultrasonic motor," IEEE Transactions on ultrasonics, ferroelectrics and frequency control, vol. 42, no. 2, Mar. 1995.

[8] Giraud, F.; Semail, B.; Audren, J.-T., "Analysis and phase control of a piezoelectric traveling-wave ultrasonic motor for haptic stick application," IEEE Transactions on Industry Applications, vol. 40, no. 6, pp. 1541-1549, Nov. Dec. 2004.

[9] F.Giraud, B.Lemaire-Semail, "Causal modeling and identification of a traveling wave ultrasonic motor," The Europeazn Physical Journal of Applied Physics, no. 2, Feb. 2003.

[10] J.Maas, P.Ide, N.Fröhleke, H.Grostollen, "Simulation model for ultrasonic motors powered by resonant converters," IAS'95, vol. 1, pp. 111120, Oct. 1995

[11] J. Wallaschek, "Contact mechanics of piezoelectric ultrasonic motors," Smart Material structures, vol. 7, pp. 369-381, 1998.

[12] X.Guillaud, P.Degobert, J.-P.Hautier, P.-J.Barre, "Synthesis of control laws with the causal ordering graph: Application to elimination of vibration in drive of mechanical laws," ICEM 2000, pp. 1917-1921, 2000.
[13] J.Maas, T.Schulte, H.Grostollen, "High performance speed control for inverter-fed ultrasonic motors optimized by a neural network," Proceeding of the International Conference on New Actuators - ACTUATOR'98, pp. 260-263, June 1998.

[14] J.Pierquin, P. Escané, A. Bouscayrol, M. Pietrzak-David, J.P. Hautier, B. De Fornel, "Behaviour model control of a high speed traction system," Proceeding of the EPE-PEMC'2000 Conference, Kocise (Slovak Republic), Sept. 2000.

[15] B.Vulturescu, A.Bouscayrol, F.Ionescu, J. P.Hautier,, "Behaviour model control for cascaded processes: application to an electrical drive," Journal of Computers and Electrical Engineering, Elsevier Science, no. 7, Oct. 2004.

[16] Y.C. Kim, L.H. Keel, S.P. Bhattacharyya, "Transient response control via characteristic ratio assignment," Procceding of the American Control Conference, Anchorage, pp. 1639-1644, May 2002.

[17] F.Giraud, B.Semail, "Position control of a small travelling wave ultrasonic motor," Proceeding of the International Conference on New Actuators - ACTUATOR'2004, June 2004.

[18] T.Senjyu, T.Kashiwagi, K.Uezato, , "Position control of ultrasonic motors using mrac and dead-zone compensation with fuzzy inference," IEEE Transactions on Power Electronics, no. 2, Mar. 2002.

[19] [Online]. Available: http://www.tky.3web.ne.jp/ usrmotor/

[20] F.Pigache, F.Giraud, B.Lemaire-Semail,, "Modelling and identification of a planar standing wave ultrasonic motor," European Physical Journal of Applied Physics, no. 1, Apr. 2006.

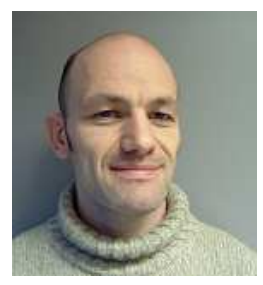

Frédéric Giraud was born in France in 1973. He is graduated from Ecole Normale Supérieure de Cachan, France in 1996 and received the B.S. degree in electrical engineering from Paris-XI University, Orsay, France in 1995, the M.S. Degree in electrical engineering in 1997 from Institut National Polytechnique de Toulouse, France, and the phD degree from Lille University, in 2002. He's a member of the electrical engineering and power electronics laboratory of Lille (L2EP) as an Associate Professeur. His research deals with the modelling and the control of standing wave and travelling wave piezo-electric actuators, for positioning and force feedback applications.

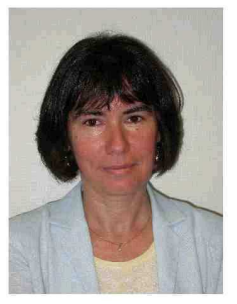

Betty Semail was born in France, in 1964. She received her $\mathrm{Ph}$. D degree in 1990 from University of Paris XI, Orsay and habilitation degree in 1997 from University of science and technologies of Lille. She is now professor in university of Lille 1 . She is member of the electrical engineering and power electronics laboratory of Lille (L2EP) and responsible of the research axis upon control of electrical systems. She has been working motors and her main field of interest now deals with the modelling and control of piezo-electric actuators, for positioning and force

feedback applications.

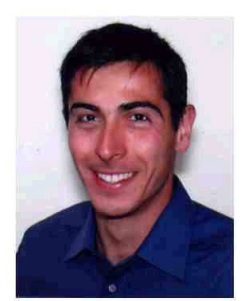

Julien Aragones was born in France in 1975, is graduated of University of Montpellier where he achived his $\mathrm{PhD}$ in automation and signal processing in 2002. He joined Sagem défense sécurité in 2003 where he works on helicopter sight heads. He is in charge of turret control for advanced studies in airborne optronic. 


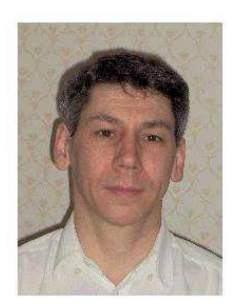

Jacques P. Robineau is gratuated of "Ecole Supérieure d'Electricité" (french top engineering school) in 1990 and achieved his $\mathrm{PhD}$ in electromagnetism. He has been working in electromagnetism numerical simulation (RF and optics) for 10 years, dealing with many aircraft and optronic laser stealth projects. He joined Sagem défense séecurité where he is in charge of advanced studies in airborne optronics.

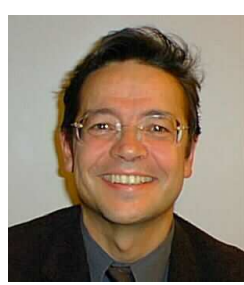

Jean-Thierry Audren was born in Paris, France on March 1st , 1951. He was graduated Engineer from Ecole Nationale Supérieure d'Electronique et d'Electromécanique de Caen in 1974. Since 1975 he has been in charge of RD in guidance, avionics and optronics systems. Since 1995 he has been leading research in the field of high power piezo motors in SAGEM. He is currently Deputy Director of the Air Land Warfare Business Unit of SAGEM, in charge of business Development. 